\title{
Methods for correcting plumage color fading in the Barn Swallow
}

\author{
Masaru HASEGAWA ${ }^{1, \#}$, Emi ARAI ${ }^{2}$, Mamoru WATANABE ${ }^{1}$ and Masahiko NAKAMURA ${ }^{2}$ \\ ${ }^{1}$ Graduate School of Life and Environmental Sciences, University of Tsukuba, Tsukuba, 1-1-1 Tennoudai, \\ Tsukuba, Ibaraki 305-8572, Japan \\ ${ }^{2}$ Laboratory of Animal Ecology, Department of Biology, Joetsu University of Education, 1 Yamayashiki-machi, \\ Joetsu, Niigata 943-8512, Japan
}

\section{ORNITHOLOGICAL SCIENCE \\ (C) The Ornithological Society of Japan 2008}

\begin{abstract}
It is necessary to correct plumage color fading when comparing the plumage coloration of birds captured at different times during the breeding season. We proposed two methods for correcting plumage color fading and compared them using the throat feathers of the Barn Swallow (Hirundo rustica gutturalis). One method uses the color shift of feathers on live birds during the same breeding season (the field method). The other method uses longitudinal color measurements of feathers placed on the open ground (the experimental method). This method has an advantage of not capturing the birds twice. The field and experimental methods estimated similar rates of fading of hue and brightness. Saturation was predicted to fade with time in the experimental method, which is unrealistic because there was no effect of time on saturation in live birds. Using the field method, we derived an equation for correcting plumage color fading in Barn Swallows. When assessing changes in plumage color, the field method should be used whenever possible since this method estimates plumage color fading in live birds.
\end{abstract}

Key words Barn Swallow, Bird coloration, Plumage color fading
Evolutionary biologists have long been interested in the evolution of brightly colored plumage (Hill \& McGraw 2006a, b). Although the plumage coloration of birds has been recognized as a fixed trait once the bird has molted, it was recently demonstrated that feather color fades after molting as a result of UV damage and abrasion (McGraw \& Hill 2004; Figuerola \& Senar 2005; Montgomerie 2006). This was because it is only during the past few years that objective methods quantifying plumage coloration has become established (Hill \& McGraw 2006a). Feather color fading predicts that early breeders have more colorful plumage than late breeders, when early breeders are captured earlier than late breeders, which is often the case in practice. This is the same prediction made by sexual selection theory, which states that colorful birds breed early in the season (Kirkpatrick et al. 1990; Hill 2002). Therefore, we should take into account the effect of time on plumage col-

(Received 16 July 2008; Accepted 5 October 2008)

\# Corresponding author, E-mail: perorobomusadiobe@gmail.com oration, particularly when comparing individuals captured at different times during the breeding season.

When comparing the plumage color in a bird species, one approach is to capture all individuals at approximately the same time (McGraw \& Hill 2004). This approach can diminish seasonal color difference between birds made by feather color fading. However, for some bird species, such an approach is not possible due to the technical difficulty. Here, we propose an alternative approach, which is to correct for the effect of time on plumage coloration. To date, this approach has not been attempted with any bird species in this young field of research. We examined two methods designed to correct for plumage color fading. One of these methods uses a shift of feather color on live birds during the same breeding season (hereafter the field method). The other method uses longitudinal color measurements of feathers placed on the open ground (hereafter the experimental method). This method has an advantage of not capturing the birds twice. We compared these two methods using the throat feathers of the Barn Swallow 
(Hirundo rustica gutturalis), a model species in sexual selection (Møller 1994). The red throat coloration of this species is known to be a sexually selected trait (Safran \& McGraw 2004; Safran et al. 2005). It is also known that swallows use phaeo-melanin to color their throats (McGraw et al. 2004). However, no studies have investigated whether the throat coloration fades with time. Therefore, we first confirmed the existence of feather color fading and then tested the two correction methods. We also studied the influences of other conditions, such as sex, year, and season, on feather color change because these may also have an influence on feather color fading (Figuerola \& Senar 2005; Safran et al. 2005).

\section{METHODS}

\section{1) General procedures}

The present study was conducted in 2006 and 2007 in a residential area of Joetsu City, Niigata Prefecture, Japan (see Tajima \& Nakamura 2003). Birds were captured by hand-net and color-ringed. The sex of an individual was determined by the presence (female) or absence (male) of an incubation patch. We collected 5-10 throat feathers from each bird.

Once in the laboratory, we piled five feathers on a piece of white paper so that there were five layers at the distal end of the feathers. The feather samples were scanned at 800 dpi resolution using an EPSON GT 9300 UF scanner, and the images obtained were imported into the Adobe Photoshop Elements 3.0 program (Adobe Systems, USA). We used a fixed number of feathers to measure plumage coloration since the number of feathers strongly influences the values of plumage color variables (Quesada \& Senar 2006). We measured the mean RGB values in a square of 30 pixels near the distal end of the feather sample. The mean RGB values were converted to hue-saturation-brightness (HSB) values using the algorithm described in Foley and Van Dam (1984). Hue (H) has normally been the parameter of interest when studying bird coloration (Hill \& McGraw 2006b). However, because the focus of this study was to correct totally for plumage color fading, we also examined the effect of time on saturation (S) and brightness (B) as well as hue. The repeatability of these variables (Lessells \& Boag 1987) was highly significant (from the whole populations in 2006 [males, H: $r$ $($ repeatability $)=0.81, \mathrm{~F}_{1,42}=9.42, \mathrm{P}<0.001 ; \mathrm{S}: \mathrm{r}=$ $0.80, \mathrm{~F}_{1,42}=9.04, \mathrm{P}<0.001 ; \mathrm{B}: \mathrm{r}=0.90, \mathrm{~F}_{1,42}=18.82$, $\mathrm{P}<0.001$; females, $\mathrm{H}$ : $\mathrm{r}=0.89, \mathrm{~F}_{1,28}=17.11, \mathrm{P}<0.001$;
$\mathrm{S}: \mathrm{r}=0.65, \mathrm{~F}_{1,28}=4.69, \mathrm{P}<0.001 ; \mathrm{B}: \mathrm{r}=0.91, \mathrm{~F}_{1,28}=$ $22.07, \mathrm{P}<0.001])$. These color variables quantify visible light only which is sufficient for this species because the throat feathers of Barn Swallows do not exhibit any UV-reflectance peak (Safran \& McGraw 2004).

\section{2) Field method}

We used birds captured twice in the same breeding season $(\mathrm{N}=32$ individuals in 2006 and $\mathrm{N}=33$ in 2007). We compared the color variables of the initial and final color scores to ascertain the existence of a color fading effect in the throat feathers of this species. We subtracted the initial from the final scores to compute the seasonal shift in plumage color. The median interval between these scores was 50 (range 6-73) in 2006 and 51 (range 9-86) in 2007.

\section{3) Experimental method}

The field experiment was carried out in 2007. We used samples collected in both 2006 and $2007(\mathrm{~N}=10$ in 2006 and $\mathrm{N}=7$ in 2007). We kept the samples in the dark prior to the experiment because long-term feather storage in the dark does not change the pigment composition of the feather samples (McGraw et al. 2004). In this experiment, we used a transparent plastic mount instead of white paper because paper cannot withstand rain in the field. Because of the pale mount coloration, the same samples gave smaller saturation and larger brightness values in the experimental method than in the field method. This difference, however, did not influence the seasonal color shift of the samples because we used the same type of mount for each set of measurements. We placed feather samples on the underside of dummy birds that were made of wood $30 \mathrm{~cm}$ in length and $3 \mathrm{~cm}$ square in crosssection. We used one sample per dummy bird (total, 17 dummy birds), each of which was placed ca. $120 \mathrm{~cm}$ above an area of open ground (see Fig. 1). We started the experiments at the beginning of April when swallows start to arrive at our study site. The color of each sample was measured at the start of the experiment and once a week during the subsequent seven weeks.

\section{4) Statistical analysis}

We used a paired $t$-test and a two-sample $t$-test to examine within-season temporal changes in plumage coloration. To more accurately predict the effect of time on color change, we used a generalized linear model with a normal error and identity link function 
to examine the relationship between color change and the interval between measurements. The intercepts were fixed at zero in this analysis, since there should be no color shifts when the interval is zero. We included the interaction terms between the interval and conditions (sex, date, and year) in the initial model. In the experimental method, we used a linear mixed model ( $\mathrm{R}$ statistical environment, function 'Ime'), which included individual feather samples as a random effect to account for repeated measures. Because the model accounts for a subject-specific random component of the residual, we can statistically control for the initial color difference among individual feather samples. We included the interaction terms between time and conditions (sex and year) in the initial model. To explore the relationship between time and color shift in each model, we used locally weighted scatter plot smoothers (LOWESS curves; cf. Safran \& McGraw 2004). These LOWESS curves enabled us to determine whether linear or other func-

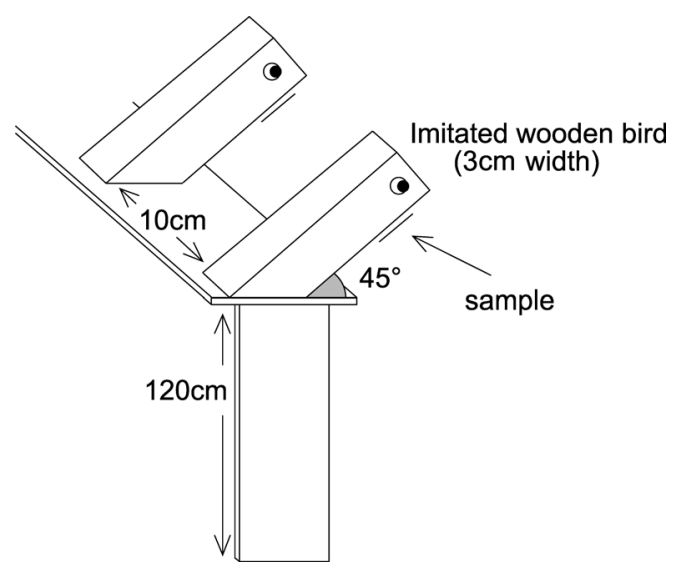

Fig. 1. Sketch of the dummy bird. The feather sample is attached to the throat part. tions, such as quadratic or exponential functions, would be suitable for modeling the relationship between two variables. All explanatory terms were initially entered into the model. The fitted model included only significant terms. In the tables presented in this paper, the statistics and $P$ values of significant terms are derived from the fitted model, whereas the statistics and $P$ values of non-significant terms are from the main term and each interaction term added separately. To compare the field and experimental methods, the color fading rate per day was estimated from the fitted model in each method. The color fading rate per day was estimated from the fading rate per week divided by 7 in the experimental method. All statistical analyses were performed using R software (http://www.cran.at.r-project.org/).

\section{RESULTS}

\section{1) Effect of color fading on each variable}

To ascertain the existence of a color fading effect in the throat feathers of this species in the field, we first compared the color variables of the initial and final color scores. Throat coloration in Barn Swallows exhibited a significant increase in hue (less red) and in brightness (paler coloration), but no change in saturation over the season (Fig. 2). There was also a significant increase in hue and brightness, but no change in saturation, when we compared the mean color variables between the initial and final scores (two-sample $t$-test, Hue: $t=-2.30, \mathrm{P}=0.02$; Saturation: $t=-0.70 ; \quad \mathrm{P}=0.49 ; \quad$ Brightness: $t=-2.19$, $\mathrm{P}=0.03)$.

\section{2) Field method}

Hue and brightness shifts were explained only by
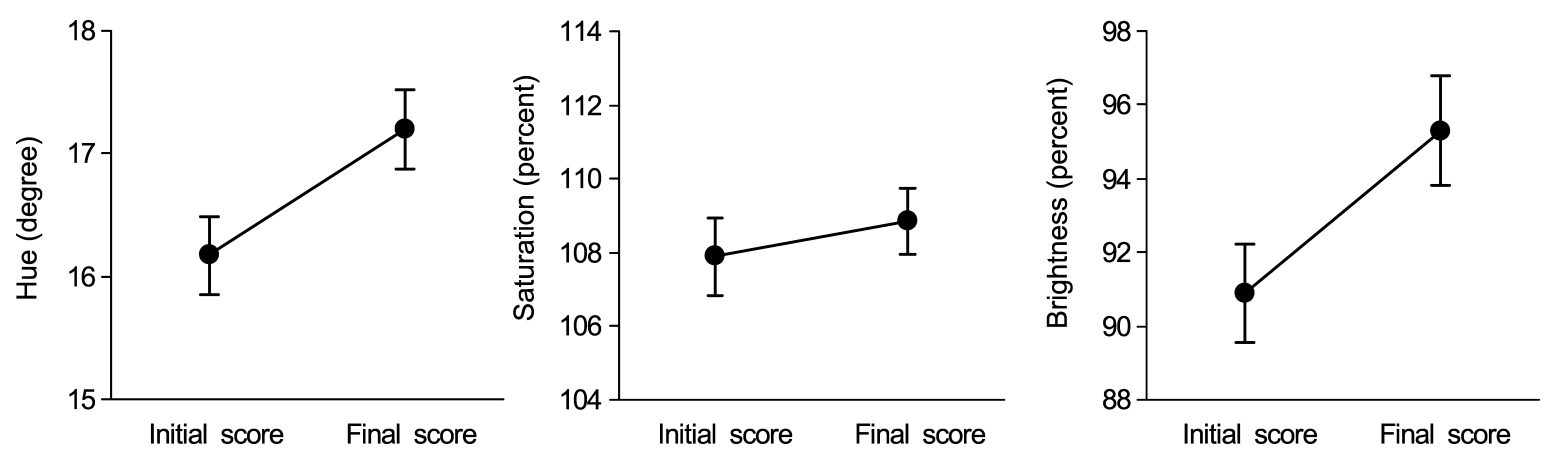

Fig. 2. Comparison of the initial and final color scores (mean $\pm \mathrm{SE}$ ). Hue: $t=-4.87, \mathrm{P}<0.0001$; Saturation: $t=-1.05, \mathrm{P}=0.30$; Brightness: $t=-6.34, \mathrm{P}<0.0001$. We used data from 65 samples collected over two years $\left(\mathrm{N}_{\delta 2006}=18, \mathrm{~N}_{\uparrow 2006}=14, \mathrm{~N}_{\delta 2007}=18, \mathrm{~N}_{+2007}=15\right)$. 
Table 1. Generalized linear model showing the effects of terms on color shift with the intercepts fixed at zero using the field method.

\begin{tabular}{lcccc}
\hline \multicolumn{1}{c}{ Model terms } & $d f$ & Effect (SE) & F & P \\
\hline Hue shift & & & & \\
$\quad$ Interval & 1 & $0.023(0.004)$ & 29.77 & $<0.0001$ \\
Interval $\times$ Sex & 1 & - & 0.32 & 0.58 \\
$\quad$ Interval $\times$ Year & 1 & - & 0.73 & 0.39 \\
$\quad$ Interval $\times$ Date & 1 & - & 0.00 & 0.96 \\
Saturation shift & & & & \\
$\quad$ Interval & 1 & - & 1.46 & 0.23 \\
Interval $\times$ Sex & 1 & - & 0.00 & 0.98 \\
$\quad$ Interval $\times$ Year & 1 & - & 0.34 & 0.56 \\
Interval $\times$ Date & 1 & - & 0.02 & 0.90 \\
Brightness shift & & & & \\
$\quad$ Interval & 1 & $0.097(0.013)$ & 26.28 & $<0.0001$ \\
Interval $\times$ Sex & 1 & - & 0.02 & 0.89 \\
Interval $\times$ Year & 1 & - & 0.01 & 0.91 \\
Interval $\times$ Date & 1 & - & 0.13 & 0.72 \\
\hline
\end{tabular}

We used a total of 65 samples $\left(\mathrm{N}_{\delta 2006}=18, \mathrm{~N}_{92006}=14\right.$, $\left.\mathrm{N}_{\delta 2007}=18, \mathrm{~N}_{\Varangle 2007}=15\right)$. The median date of the initial scoring was 21 May (range 28 April-12 June) in 2006, and 22 April (range 28 March-31 May) in 2007.

Table 2. Generalized linear mixed model showing the effects of terms on color shift using the experimental method.

\begin{tabular}{lccrc}
\hline \multicolumn{1}{c}{ Model terms } & $d f$ & Effect $(\mathrm{SE})$ & $\mathrm{F}$ & $\mathrm{P}$ \\
\hline Hue & & & & \\
$\quad$ Time & 1 & $0.17(0.03)$ & 39.12 & $<0.0001$ \\
Time $\times$ Sex & 1 & - & 0.05 & 0.82 \\
$\quad$ Time $\times$ Year & 1 & - & 0.76 & 0.39 \\
Saturation & & & & \\
$\quad$ log (Time) & 1 & $2.50(0.36)$ & 47.14 & $<0.0001$ \\
$\log ($ Time $) \times$ Sex & 1 & - & 0.98 & 0.33 \\
log (Time) $\times$ Year & 1 & - & 0.94 & 0.33 \\
Brightness & & & & \\
Time & 1 & $0.68(0.11)$ & 41.72 & $<0.0001$ \\
Time $\times$ Sex & 1 & - & 0.05 & 0.82 \\
Time $\times$ Year & 1 & - & 0.93 & 0.34 \\
\hline
\end{tabular}

Individuals were treated as random effects.

We used a total of 17 samples $\left(\mathrm{N}_{\delta 2006}=6, \mathrm{~N}_{\$ 2006}=4, \mathrm{~N}_{\delta 2007}=6\right.$, $\mathrm{N}_{\text {†2007 }}=1$ ).

the interval between measurements (Table 1). These variables faded linearly with time (Fig. 3). There was no significant effect of the interaction between the interval and the three conditions (sex, year, and initial capture date). The saturation shift was not explained by any term (the main effect of the interval or its interaction with sex, year, and initial capture date; see
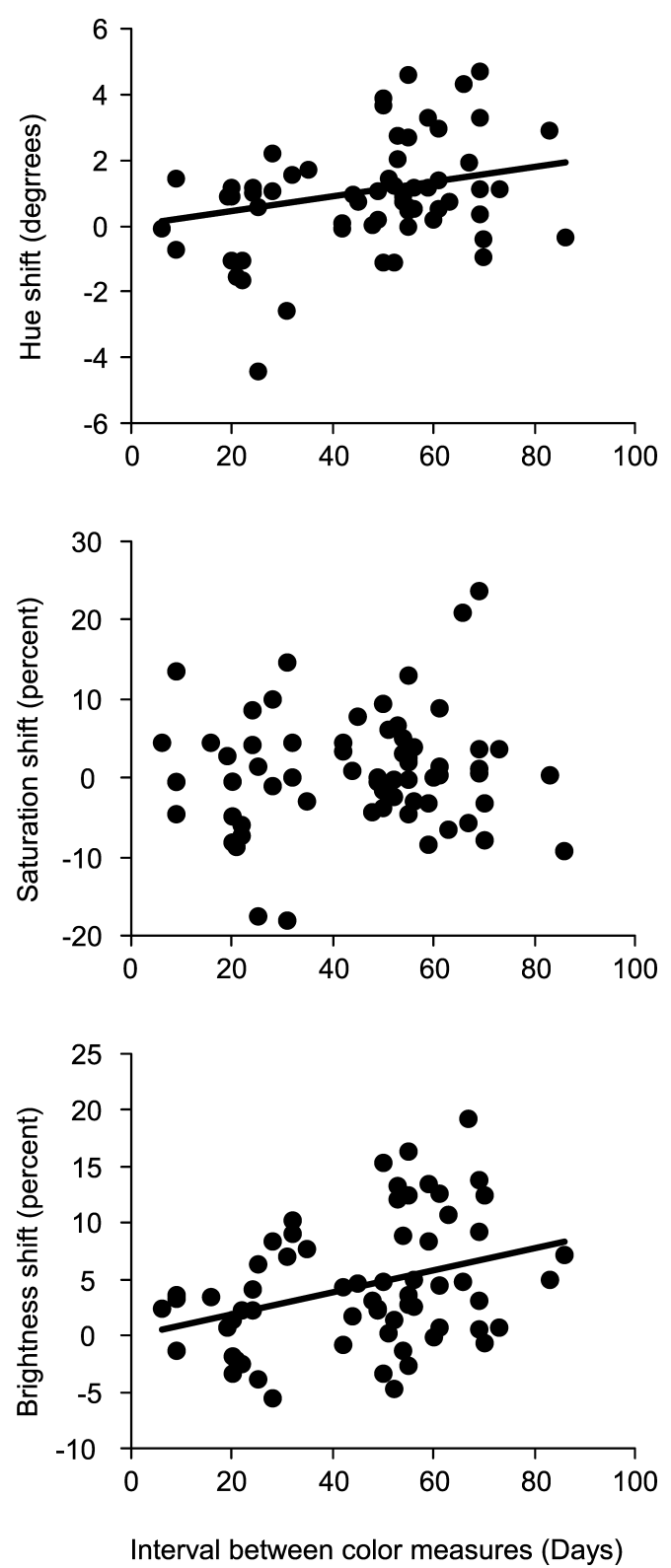

Fig. 3. Relationship between plumage hue (upper), saturation (middle), and brightness (bottom), and the interval between color measurements in the field. Higher hue, saturation, and brightness scores indicate that the color faded to a greater extent. Regression lines are from the fitted model using a generalized linear model with the intercept fixed at zero (Table 2).

Table 1).

\section{3) Experimental method}

All color variables were significantly explained only by time (Table 2). Although hue and brightness faded linearly with time, saturation faded curvilinearly (Fig. 4). For all three color variables, there was 

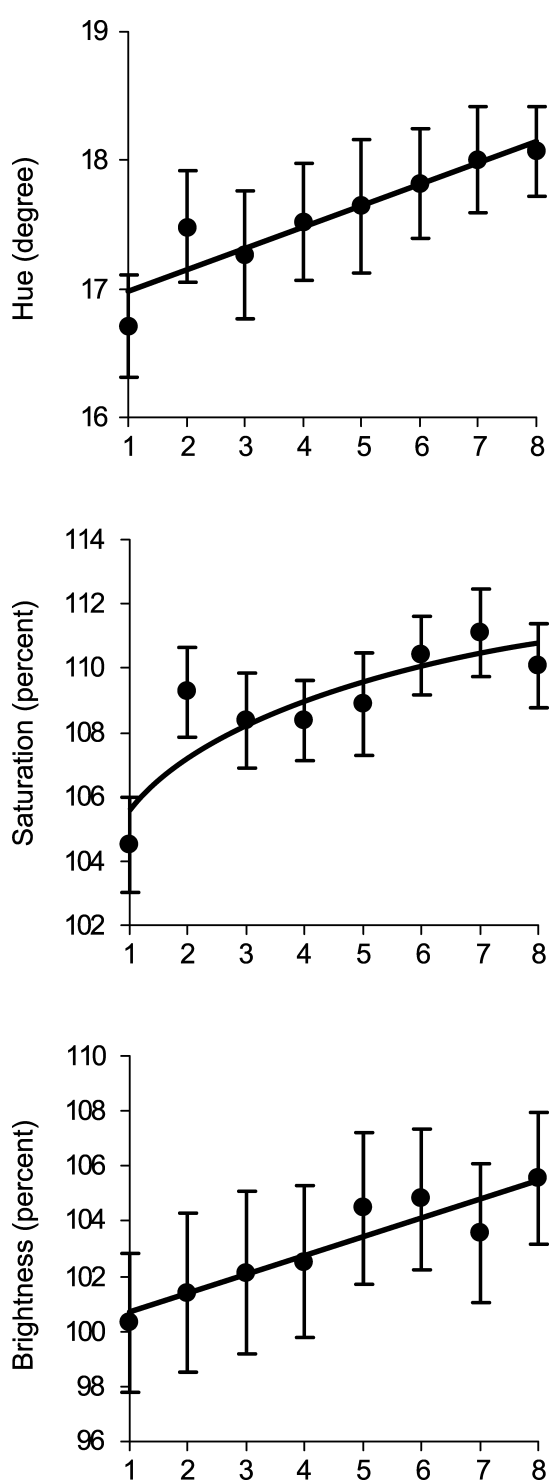

Fig. 4. Relationship between plumage hue (upper), saturation (middle), and brightness (bottom), and the weeks since the start of the experiment. Higher hue, saturation, and brightness scores indicate that the color faded to a greater extent. Regression lines are from the fitted model using a generalized linear mixed model (Table 3). Intercepts, which were also predicted from the models, were as follows: 16.82 for hue, 105.56 for saturation, and 100.00 for brightness. Bars depict \pm SE.

no significant effect of the interaction between time and the conditions (sex and year; Table 2).

\section{4) Comparing the estimates from the two meth- ods}

The two methods predicted similar rates of hue and brightness fading (Table 3). In contrast, for saturation, the two methods yielded different predictions.
Table 3. Feather color fading rates estimated using the two methods.

\begin{tabular}{lcc}
\hline \multicolumn{1}{c}{ Color variables } & $\begin{array}{c}\text { Field method } \\
(65)\end{array}$ & $\begin{array}{c}\text { Experimental } \\
\text { method }^{\mathrm{a}} \\
(17)\end{array}$ \\
\hline $\begin{array}{l}\text { Hue (degree/day) } \\
\text { Saturation (percent/day) }\end{array}$ & $\begin{array}{c}0.023( \pm 0.004) \\
0^{\mathrm{b}}\end{array}$ & $0.024( \pm 0.004)$ \\
Brightness (percent/day) & $0.097( \pm 0.013)$ & $0.098( \pm 0.015)$ \\
\hline
\end{tabular}

Numbers in parentheses indicate sample sizes.

${ }^{a}$ Estimates are calculated by the feather fading rate per week divided by 7 .

${ }^{\mathrm{b}}$ There is no significant effect of time on this variable.

${ }^{\mathrm{c}}$ We were unable to estimate the fading rate because of the curvilinearity.

Although the field method predicted no significant effect of time on saturation, the experimental method predicted a significant effect of time on saturation in a curvilinear form.

\section{DISCUSSION}

Hue and brightness faded within individuals as well as at the population level over the season (Fig. 2 ). Although the measured effect of time on coloration was highly variable among birds, some seasonal trends were observed (Fig. 3). A method is needed for removing the effect of feather color fading in this species so as not to confuse this effect with other effects (e.g. age and/or attractiveness at mating). Both correction methods predicted that hue and brightness fade linearly with time (Figs. 3 and 4). Although year, season, and sex have been predicted to affect the rate of feather color fading (Delhey et al. 2006; Safran et al. 2006), these factors did not influence the color fading rate in the present study (Tables 1 and 2). Therefore, we can correct hue and brightness only with time in Barn Swallows.

Saturation can be used without correcting the effect of time in this species because this variable had no consistent effect over time (Figs. 2 and 3). On the other hand, the experimental method predicted that saturation fades with time (Fig. 4). This might be due to the difficulty of simulating field conditions using the experimental method. Specifically, it is not possible to take into account bird behavior using this method, unlike the field method that directly measured the seasonal color change in birds. It has been demonstrated that birds can control their plumage coloration by behavior and the use of preening oil 
(Montgomerie et al. 2001; Surmacki \& Nowakowski 2007). Another explanation is that we cannot detect complex patterns of saturation fading using the field method. However, this is improbable, because we included three interaction terms, and there was still no significant effect of time (Table 1).

Using the field method, we devised the following equation to correct plumage color fading in the throat feathers of the Barn Swallow:

$$
\begin{aligned}
& \text { Corrected }(\mathrm{H}, \mathrm{S}, \mathrm{B}) \\
& \quad=\text { measured }(\mathrm{H}, \mathrm{S}, \mathrm{B})-(0.023,0,0.097) \times \text { Days }
\end{aligned}
$$

Here, $\mathrm{H}, \mathrm{S}$, and $\mathrm{B}$ represent hue, saturation, and brightness, respectively. The term "Days" indicates the days elapsed from the capture date of the first bird to that of each bird. Although we could correct plumage coloration only with time in the present study, there are probably other instances in which other factors, such as sex, year, and season, have an influence on color fading rates. In these instances, we could correct plumage color fading with an equation that includes significant interaction terms in addition to time itself. Therefore, we can correct plumage coloration under all circumstances.

One of the requirements for using the field method is that it is necessary to capture birds twice each season. If this cannot be achieved, then it is necessary to use the experimental method for correcting seasonal color change. As mentioned in the second paragraph of the discussion, this method might fail to estimate actual feather color fading in the field. Therefore, if it is necessary to use the experimental method, careful consideration would need to be given to the estimates obtained using this method.

\section{ACKNOWLEDGEMENTS}

We are grateful to the residents of Joetsu City for their kind support and assistance. We also thank the members of the Laboratory of Animal Ecology of Joetsu University of Education and the Laboratory of Conservation Ecology of University of Tsukuba.

\section{REFERENCES}

Delhey K, Peters A, Johnsen A \& Kempenaers B (2006) Seasonal changes in blue tit crown color: do they signal individual quality? Behav Ecol 17: 790-798.

Figuerola J \& Senar JC (2005) Seasonal changes in carotenoid- and melanin-based plumage coloration in the Great Tit Parus major. Ibis 147: 797-802.

Foley JD \& van Dam A (1984) Intensity and color. In:
Fundamentals of interactive computer graphics. pp 593-622. Addison-Wesley, Boston.

Hill GE (2002) A red bird in a brown bag: the function and evolution of colorful plumage in the house finch. Oxford Univ Press, Oxford.

Hill GE \& McGraw KJ (2006a) Bird coloration. I. Mechanisms and measurements. Harvard Univ Press, Cambridge.

Hill GE \& McGraw KJ (2006b) Bird coloration. II. Function and evolution. Harvard Univ Press, Cambridge.

Kirkpatrick M, Price T \& Arnold SJ (1990) The Darwin-Fisher theory of sexual selection in monogamous birds. Evolution 44: 180-193.

Lessells CM \& Boag PT (1987) Unrepeatable repeatabilities: a common mistake. Auk 104: 116-121.

McGraw KJ \& Hill GE (2004) Plumage color as a dynamic trait: carotenoid pigmentation of male house finches (Carpodacus mexicanus) fades during the breeding season. Can J Zool 82: 734-738.

McGraw KJ, Safran RJ, Evans MR \& Wakamatsu K (2004) European barn swallows use melanin pigments to color their feathers brown. Behav Ecol 15: 889-891.

Møller AP (1994) Sexual selection and the barn swallow. Oxford Univ Press, Oxford.

Montgomerie R (2006) Cosmetic and adventitious colors. In: Hill GE \& McGraw KJ (eds) Bird coloration. II. Function and evolution. pp 399-427. Harvard Univ Press, Cambridge.

Montgomerie R, Lyon B \& Holder K (2001) Dirty ptarmigan: Behavioral modification of conspicuous male plumage. Behav Ecol 12: 429-438.

Quesada J \& Senar JC (2006) Comparing plumage colour measurements obtained directly from live birds and from collected feathers: the case of the great tit Parus major. J Avian Biol 37: 609-616.

Safran RJ \& McGraw KJ (2004) Plumage coloration, not length or symmetry of tail-streamers, is a sexually selected trait in North American barn swallows. Behav Ecol 15: 455-461.

Safran RJ, Neuman CR, McGraw KJ \& Lovette IJ (2005) Dynamic paternity allocation as a function of male plumage color in barn swallows. Science 309: 2210-2212.

Surmacki A \& Nowakowski JK (2007) Soil and preen waxes influence the expression of carotenoid-based plumage coloration. Naturwissenschaften 94: 829-835.

Tajima K \& Nakamura M (2003) Response to manipulation of partner contribution: A handicapping experiment in the Barn Swallow. Ornithol Sci 2: 65-72. 